\title{
Meningococcal Meningitis in College Students at United States Universities
}

\author{
Mikafui Drotsi* \\ College of Public Health, Obio State University, Columbus, $\mathrm{OH}$ \\ https:/ / doi.org/10.33697/ ajur.2020.007 \\ Student:dఇotsi.2@buckeyemail.osu.edu* \\ Mentor: harris.44@osu.edu
}

\begin{abstract}
The purpose of this study was to review current United States (US) university meningitis prevention and awareness efforts for college students with the objective of finding improved methods for meningitis control on college campuses. Meningococcal meningitis cases occurring amongst the students at 45 US universities, reported by the National Meningitis Association between 2013-2017, were reviewed. Apart from analyzing the incidence of meningococcal serotype cases and prevention protocols at the 45 US universities, interviews were conducted with university health directors and health center staff to assess the nature of meningitis control programs on college campuses. Of the 45 US universities reported between the years, 2013-2017, 20 universities had cases of Meningococcal meningitis serotype B (Men B) while 25 universities had cases of serotype A (Men A), C (Men C), W (Men W), or Y (Men Y). Among 80 cases across all US universities, there were 11 deaths for a case fatality rate of $11 / 80$ $(14 \%)$. While all universities adhere to state requirements of immunization against serotypes $\mathrm{A}, \mathrm{C}, \mathrm{W}$ and $\mathrm{Y}$, the vaccine for Men $\mathrm{B}$ was only recently FDA approved and is not widely used. Further review of some university meningitis prevention and awareness efforts reveal a trend in more passive (e.g. posters, pamphlets, health portal guidance) approaches, while the uptake of active campaign efforts (e.g. vaccination drives, presentations) are not always prioritized until outbreaks occur.
\end{abstract}

\section{KEYWORDS}

Awareness; Epidemiology; Disease; Meningococcal; Prevention; Serotype; University; Vaccination

\section{INTRODUCTION}

Meningococcal meningitis is a highly contagious Neisseria meningitidis (N. meningitidis) bacterial infection (case fatality- 10-15\%), that causes inflammation of the brain and spinal cord. Given the relatively high case fatality rate and disability ratio of $11-19 \%,{ }^{1}$ efficient surveillance methods and fast response efforts are a necessity. Infection of the meninges of the brain and spinal cord can cause severe chronic effects including nerve damage, paralysis, hearing loss and life-threatening septicemia. ${ }^{2}$ Based on characteristics of $N$. meningitidis polysaccharide capsules, the bacteria can be classified into different serogroups. Although there are at least 13 knowledgeable serogroups, this study only focused on serogroups A, B, C, W-135, and Y. In the US, meningococcal Serogroups B and C account for $60 \%$ of meningococcal cases each year. ${ }^{3}$ While new strains of serogroup A meningococcus (Men A), serogroup C meningococcus (Men C), serogroup W meningococcus (Men W), and serogroup Y meningococcus (Men Y) all remain a threat, serogroup $\mathrm{B}$ carries high importance given its antigenic mimicry of human neural tissue antigens. ${ }^{4}$

Transmission of N. meningitidis is mainly through direct contact and droplets. ${ }^{5}$ N. meningitidis colonizes mucosal surfaces of the nasopharynx primarily through horizontal genetic exchange. To mitigate the transmission rate of N. meningitidis, a common method for treatment and control of the disease, is the use of antibiotics. Nevertheless, increasing virulence seen in $N$. meningitidis, is a direct result of evolved genetic mechanisms that have led to antibiotic resistance. ${ }^{5}$ As a result, there is no guarantee that antibiotics prescribed for treatment (cefotaxime or ceftriaxone) ${ }^{6}$ or even current meningococcal vaccines are effective. Transmission through droplets occurs by the diffusion of large- droplets through respiratory tract or throat secretions from host to host, including those of asymptomatic carriers. ${ }^{1}$ Unvaccinated and immunocompromised individuals are the most susceptible. ${ }^{2}$ Even though meningococcal disease is rather rare and on the decline, college students who often live in dormitories or close quarters, remain one of the most susceptible populations. ${ }^{7}$

Over the years, the World Health Organization (WHO) and Centers for Disease Control (CDC) have worked alongside state health departments to improve meningococcal disease vaccination programs. The meningococcal conjugate vaccines (Menactra, Menveo, and MenHibrix), instituted in the US in 2005, have continued to help decrease meningococcal disease cases and outbreaks by $80 \% .^{1}$ The US Health Department recommends that all adolescents receive a dose of Men ACWY at 11 or 12 years old, followed by a second dose or booster at the age of 16. In addition, the Advisory Council on Immunization Practices (ACIP) recommends administration of Men ACWY booster vaccines at times of increased meningococcal incidence (e.g. first year 
university students living in residence halls, high risk individuals). ${ }^{8}$ Vaccination proves to be the best prevention for disease, and as a result mass vaccination could be the best solution. Nevertheless, vaccination campaigns can be very expensive, as seen by the potential administration of 300,000-500,000 doses per year costing almost 1.8 million dollars. ${ }^{8}$ It is important to note, however, that before the use of the meningococcal conjugate (Men ACWY) vaccines in adolescents was recommended, the overall annual incidence of meningococcal disease had already decreased by approximately 64\% between 1996 and $2005 .{ }^{1}$ Thus, while vaccination may aid in decreasing rates of meningococcal disease, other preventive measures such as better sanitation and decreased crowding, have played a more critical role. ${ }^{8}$

In addition to addressing meningococcal $\mathrm{A}, \mathrm{C}, \mathrm{W}$, or $\mathrm{Y}$ prevention, outbreaks of serotype meningococcal $\mathrm{B}$ at prestigious US universities such as Princeton University (New Jersey) and the University of California Santa-Barbara (California) campus between 2013-2014, inspired a push for serotype B vaccination. Individuals at increased risk for meningococcal serotype B are encouraged to take the serogroup B meningococcal vaccines (Bexsero and Trumenba). ${ }^{9}$ Although both vaccines have been deemed effective by the FDA, to date, there is still little data available on vaccine effectiveness against clinical disease or duration of protection against clinical disease. ${ }^{10}$

Even though cases of meningococcal disease also occur outside of university environments, factors within university settings make certain university populations more susceptible to contraction of the disease. In addition, living arrangements, also make university students vulnerable. According to the US News Annual Survey on college student living numbers, in 2015, on average, approximately $39 \%$ of university students lived on campus. ${ }^{11}$ Although some students are supplied with single room accommodation, many students are forced to share a room with their peers. As a result, majority of these rooms are limited in space, which may allow for easy transmission of bacterial N. meningitidis droplets. Increased risk factors for meningococcal disease may also include social life and habits (e.g. drinking, more than one kissing partner, sharing drinks), HIV infection, or travel to places where meningococcal disease is common. ${ }^{12}$ Over the past few years, cases and outbreaks have continued to occur at universities including cases at Rutgers University, University of Oregon and many others (see Table 2).

Even though meningococcal disease is on the decline as a whole, ${ }^{1}$ this study works to identify incidence of cases and US university prevention methods, so as to decrease future cases.

\section{METHODOLOGY}

In this study, universities used as case studies were specifically universities that reported meningococcal cases to the National Meningitis Association (NMA) between March 2013 and November 2017. 13 US university meningococcal cases reported to the NMA between these years, totaled 80 cases. University and state immunization requirements and outbreak protocols were compared and analyzed to determine effectiveness in preventing meningococcal serotypes (e.g. Men A, B, C, W, Y). In addition, university active or passive prevention efforts were also analyzed. Active approaches were defined as efforts that included campaign or vaccination drives and/ or health presentations. Passive approaches were defined by the presence of posters, information on health center portals, and distribution of pamphlets.

For this study 45 (NMA Official Meningococcal Outbreak Reported) US universities were analyzed, all spanning 22 US states (see Table 1 and Table 2). Of the 45 universities, 20 universities had cases of viral meningococcal B serotype, while 25 of the universities had cases reported as either Men A, C, W, or Y serotype cases. Meningococcal outbreak information for each university were retrieved from the NMA, in addition to the CDC and directly from university health centers. University meningitis immunization requirements were gathered through university health center websites and student mandatory immunization lists, while state meningitis immunization requirements were retrieved through the National Meningitis Association and State Health Department Immunization Requirement Records.

For further analysis of university prevention and awareness efforts, university health directors or health center staff (of the 45 universities analyzed), were all contacted and sent a recruitment letter to serve as case studies for the cases that occurred on their campuses. This was approved through exempt IRB permissions (00006378). Only ten university health directors or health center staff members were included in the study. These university health directors or health center staff members were from a series of seven US universities (University of Oregon, University of California Santa Barbara, Missouri University, Kalamazoo College, Palomar Community College, Georgia Tech, and West Chester University). All these universities were chosen as case studies. Each of the university health directors or health center staff members agreeing to partake in an interview were asked five questions over a 30-40 minute interview period. All interviews were conducted over phone conference between Summer 2016 and Winter 2017. To identify methods for improved prevention of meningococcal disease prevention and response on university campuses, international meningitis organizations and national university health organizations were also interviewed. Organizations interviewed included Meningitis Now, National Meningitis Research Foundation, American College Health Association, and the 
National Meningitis Association. Each individual interviewed in this study chose to remain anonymous. To protect their rights and privacy no profiles will be released.

\section{RESULTS}

As shown in Table 2, between 2013 and 2017, 20 US universities had Men B cases, while 25 had non-serogroup B cases or unspecified serotype cases. Overall, this amounted to 80 cases across the 45 US universities, displayed in Table 1 . Of all the 45 universities reported to have had meningococcal disease cases, five universities were reported to have had outbreaks. All outbreaks reported were caused by the spread of serotype B meningococcal disease. Out of all states with university meningococcal disease cases, it is evident that California had the highest number of Men $\mathrm{B}$ cases $(\mathrm{N}=16 / 52,31 \%)$. Further, there were more Men B cases than non-serogroup B cases amongst Californian universities (see Table 1).

\begin{tabular}{|c|c|c|c|}
\hline U.S. State & $\begin{array}{c}\text { \# of Cases of A, C, W, Y/ } \\
\text { Unknown Serotype }\end{array}$ & \# of Cases of B Serotype & Total Meningococcal Cases \\
\hline Alabama & 1 & 0 & 1 \\
\hline Arizona & 1 & 0 & 1 \\
\hline Atlanta & 1 & 0 & 1 \\
\hline California & 4 & 16 & 20 \\
\hline Connecticut & 1 & 0 & 1 \\
\hline Connecticut & 2 & 0 & 2 \\
\hline Florida & 1 & 0 & 1 \\
\hline Idaho & 1 & 0 & 1 \\
\hline Illinois & 1 & 1 & 2 \\
\hline Iowa & 1 & 0 & 1 \\
\hline Massachusetts & 1 & 0 & 1 \\
\hline Massachusetts & 0 & 2 & 2 \\
\hline Michigan & 0 & 1 & 1 \\
\hline Missouri & 0 & 1 & 1 \\
\hline New Jersey & 0 & 10 & 10 \\
\hline New York & 2 & 0 & 2 \\
\hline North Carolina & 2 & 0 & 2 \\
\hline Ohio & 1 & 0 & 1 \\
\hline Oregon & 0 & 12 & 12 \\
\hline Pennsylvania & 5 & 2 & 7 \\
\hline Rhode Island & 0 & 2 & 2 \\
\hline South Dakota & 1 & 0 & 1 \\
\hline Virginia & 1 & 0 & 1 \\
\hline Washington D.C. & 0 & 1 & 1 \\
\hline Wisconsin & 1 & 4 & 5 \\
\hline Totals & 28 & 52 & 80 \\
\hline
\end{tabular}

Table 1. Comprehensive Summary of Cases of Meningococcal Meningitis in College Students at United States Universities by State (2013-2017) ${ }^{13}$

\section{Protocol/Vaccination Requirements}

Based on much of the data collected from interviews and research literature, vaccination requirements amongst the majority of US universities affected by meningococcal disease cases between 2013 and 2017 were similar. According to data collected from specific university meningococcal disease protocol and immunization requirements, approximately $84 \%(\mathrm{~N}=38)$ of the 45 universities studied, required Men ACWY conjugate vaccination. It is important to note, however, that while some universities may have required the Men ACWY vaccination, it may not have been required for all the undergraduate student population. An example of this was University of Missouri where Men ACWY vaccination was only required for students living in university housing, ${ }^{14}$ rather than the whole undergraduate student population. While all universities followed their state health policies and immunization requirements, not all universities had Men ACWY vaccination requirements. ${ }^{13}$ As a result, some universities chose to follow ACIP vaccination guidelines and require Men ACWY vaccination, regardless of whether their state required it or not. ${ }^{15}$ According to National Meningitis Association geographical maps, the requirement of meningococcal vaccination is most prominent amongst mid-western and eastern states. ${ }^{13}$ In addition, while some states require universities to mandate Men ACWY vaccination before entering college $(66 \%, \mathrm{~N}=33)$, other states either require awareness and prevention education or have no requirements at all (see Figure 1). 


\begin{tabular}{|c|c|c|c|c|}
\hline Name of US University & State & Outbreak Year & \# of Cases at University & Serotype \\
\hline Auburn University & Alabama & 2016 & 1 & A,C, W, Y/ Unknown \\
\hline Bucknell University & Pennsylvania & 2017 & 2 & A,C, W, Y/ Unknown \\
\hline Cal Poly & California & $\begin{array}{c}1 \text { case }(2015) \\
2 \text { cases }(2017) \\
\end{array}$ & 3 & $\mathrm{~B}$ \\
\hline $\begin{array}{c}\text { Dakota Wesleyan } \\
\text { University }\end{array}$ & South Dakota & 2015 & 1 & A,C, W, Y/ Unknown \\
\hline Drexel University & Pennsylvania & 2014 & 1 & $\mathrm{~B}$ \\
\hline Elon College & North Carolina & 2017 & 1 & $\mathrm{~A}, \mathrm{C}, \mathrm{W}, \mathrm{Y} / \mathrm{Unknown}$ \\
\hline Georgetown University & Washington D.C. & 2014 & 1 & $\mathrm{~B}$ \\
\hline Georgia Tech * & Atlanta & 2013 & 1 & $\mathrm{~A}, \mathrm{C}, \mathrm{W}, \mathrm{Y} / \mathrm{Unknown}$ \\
\hline Humbolt State University & California & 2014 & 1 & $\mathrm{~A}, \mathrm{C}, \mathrm{W}, \mathrm{Y} / \mathrm{Unknown}$ \\
\hline $\begin{array}{l}\text { John Tyler Community } \\
\text { College }\end{array}$ & Virginia & 2015 & 1 & A,C, W, Y/ Unknown \\
\hline Kalamazoo College * & Michigan & 2013 & 1 & $\mathrm{~B}$ \\
\hline Kutztown University & Pennsylvania & 2014 & 1 & B \\
\hline Loyola University & Illinois & 2013 & 1 & $\mathrm{~A}, \mathrm{C}, \mathrm{W}, \mathrm{Y} / \mathrm{Unknown}$ \\
\hline Marquette University & Wisconsin & 2015 & 1 & A,C, W, Y/ Unknown \\
\hline Missouri University * & Missouri & UNKNOWN & 1 & $\mathrm{~B}$ \\
\hline Northeastern University & Massachusetts & 2016 & 1 & $\mathrm{~A}, \mathrm{C}, \mathrm{W}, \mathrm{Y} / \mathrm{Unknown}$ \\
\hline $\begin{array}{c}\text { Northern Arizona } \\
\text { University }\end{array}$ & Arizona & 2017 & 1 & A,C, W, Y/ Unknown \\
\hline Ohio University & Ohio & 2017 & 1 & A,C, W, Y/ Unknown \\
\hline Oregon State University & Oregon & 2017 & 5 & $\mathrm{~B}$ \\
\hline $\begin{array}{l}\text { Palomar Community } \\
\text { College } *\end{array}$ & California & 2014 & 1 & $\mathrm{~B}$ \\
\hline Penn State University & Pennsylvania & 2016 & 2 & A,C, W, Y/ Unknown \\
\hline Princeton University & New Jersey & 2013 & 8 & $\mathrm{~B}$ \\
\hline Providence College & Rhode Island & 2015 & 2 & $\mathrm{~B}$ \\
\hline Rutgers University & New Jersey & 2016 & 2 & $\mathrm{~B}$ \\
\hline Santa Barbara City College & California & 2017 & 1 & $\mathrm{~B}$ \\
\hline Santa Clara University & California & 2016 & 3 & $\mathrm{~B}$ \\
\hline San Diego State University & California & 2014 & 1 & $\mathrm{~B}$ \\
\hline Seminole State College & Florida & 2014 & 1 & A,C, W, Y/ Unknown \\
\hline St. Ambrose University & Iowa & 2016 & 1 & $\mathrm{~A}, \mathrm{C}, \mathrm{W}, \mathrm{Y} / \mathrm{Unknown}$ \\
\hline St. Mary's College & California & 2015 & 1 & A,C, W, Y/ Unknown \\
\hline $\begin{array}{c}\text { State University College of } \\
\text { Oswego }\end{array}$ & New York & 2013 & 1 & A,C, W, Y/ Unknown \\
\hline $\begin{array}{c}\text { University of California, } \\
\text { Santa Barbara * }\end{array}$ & California & 2013 & 6 & $\mathrm{~B}$ \\
\hline $\begin{array}{c}\text { University of California, } \\
\text { Berkeley }\end{array}$ & California & 2017 & 1 & A,C, W, Y/ Unknown \\
\hline $\begin{array}{c}\text { University of California, } \\
\text { Davis }\end{array}$ & California & 2015 & 1 & B \\
\hline $\begin{array}{c}\text { University of California, } \\
\text { Long Beach }\end{array}$ & California & 2013 & 1 & A,C, W, Y/ Unknown \\
\hline University of Hartford & Connecticut & 2014 & 1 & A,C, W, Y/ Unknown \\
\hline University of Idaho & Idaho & 2014 & 1 & $\mathrm{~A}, \mathrm{C}, \mathrm{W}, \mathrm{Y} / \mathrm{Unknown}$ \\
\hline University of Illinois & Illinois & 2017 & 1 & $\mathrm{~B}$ \\
\hline $\begin{array}{c}\text { University of } \\
\text { Massachusetts, Amherst }\end{array}$ & Massachusetts & 2017 & 2 & 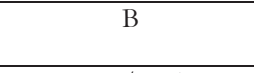 \\
\hline $\begin{array}{l}\text { University of North } \\
\text { Carolina, Charlotte }\end{array}$ & North Carolina & UNKNOWN & 1 & A,C, W, Y/ Unknown \\
\hline University of Oregon * & Oregon & 2015 & 7 & $\mathrm{~B}$ \\
\hline University of Rochester & New York & 2015 & 1 & $\mathrm{~A}, \mathrm{C}, \mathrm{W}, \mathrm{Y} / \mathrm{Unknown}$ \\
\hline $\begin{array}{c}\text { University of Wisconsin } \\
\text { Madison } \\
\end{array}$ & Wisconsin & $\begin{array}{l}2010 \text { (1 case }) \\
2014 \text { ( } 3 \text { cases }) \\
\end{array}$ & 4 & $\mathrm{~B}$ \\
\hline West Chester University* & Pennsylvania & 2013 & 1 & A,C, W, Y/ Unknown \\
\hline Yale University & Connecticut & 2016 & 2 & $\mathrm{~A}, \mathrm{C}, \mathrm{W}, \mathrm{Y} / \mathrm{Unknown}$ \\
\hline
\end{tabular}

Table 2. Cases of Meningococcal Meningitis in College Students at United States Universities (2013-2017) ${ }^{13}$ 


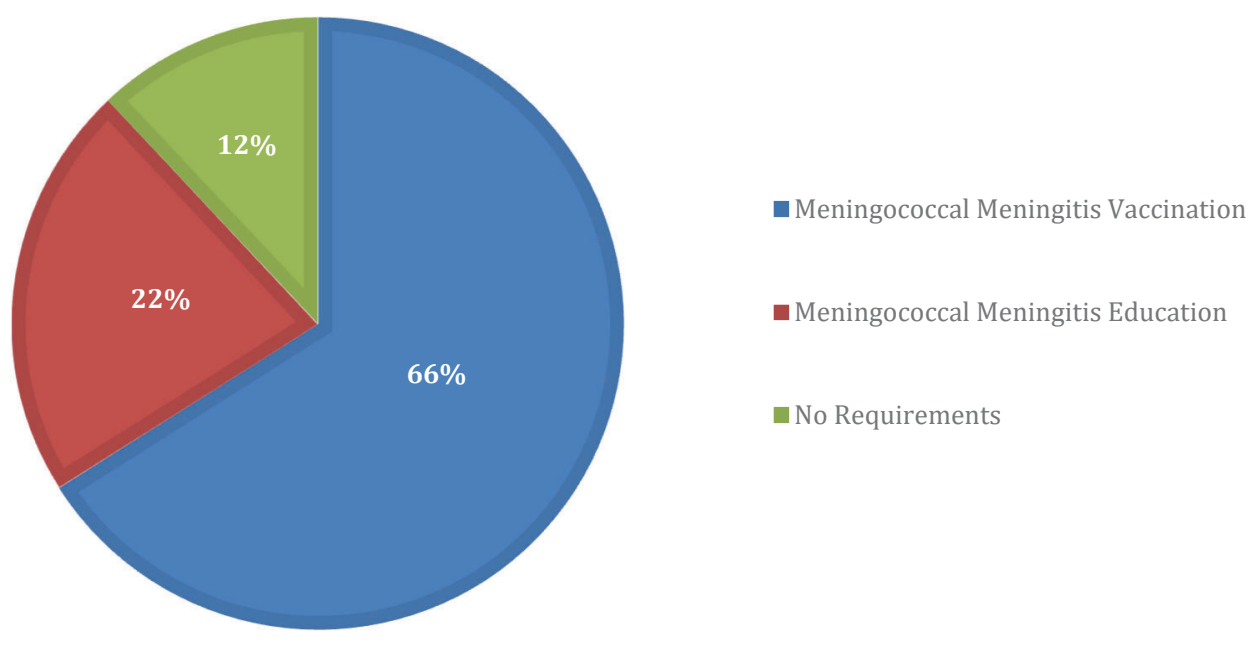

Figure 1. Meningococcal Meningitis State Health Department Prevention Requirement Distributions Across All United States, National Meningitis Association ${ }^{13}$

Apart from requiring general meningococcal vaccination, knowledge of the types of meningococcal vaccination required is critical. While many universities required the Men ACWY vaccination, Men B vaccination was also recommended. Even though all the universities that were specifically interviewed and utilized as case studies recommended Men B vaccination to their students, many university health directors and staff stated that it would be unlikely for them to require Men B vaccination in addition to Men ACWY vaccination. Other explanations for only recommending the Men B vaccination might have been due to ACIP guidelines. ${ }^{1}$ According to the ACIP, although several small outbreaks occurred on college campuses after 2013, college students in general were not at higher risk of meningococcal serogroup B disease than persons of the same age who are not college students. ${ }^{1}$ Consequently, ACIP did not routinely recommend Men B vaccination for college students. However, college students could choose to receive Men B vaccination to reduce their risk of meningococcal serogroup B disease. ${ }^{16}$ Interviews with Meningitis Now, the Meningitis Research Foundation, and university health directors and staff revealed lower Men B vaccination uptake given personal out of pocket expenses and limited research on the effectiveness of Men B vaccination.

Although immunization protocols were a large focus for prevention efforts amongst case study universities, university health staff recognized that more needed to be done in terms of prevention and awareness for students, given evident case occurrences, irrespective of having immunization requirements or not (see Figure 2). ${ }^{17-23}$ While $21 \%$ of case events amongst US universities (2013-2017), occurred at universities without Men B and/or Men ACWY vaccination recommendations or requirements, $76 \%$ of case events occurred at universities with Men B and/or Men ACWY vaccination recommendation or requirements.

\section{Awareness/Campaign Result}

After conducting interviews with student health center directors and staff, amongst universities used as case studies, it became evident that the majority of awareness campaigns for the prevention of meningococcal disease on campuses is through passive approaches as opposed to active ones. Five of eight case study universities voiced using more passive approaches, while the remainder utilized additional active approaches (Figure 3). ${ }^{17-23}$ Specific passive approaches tended to include sharing of meningococcal disease symptoms and vaccination information through online portals. When asked why more passive approaches were taken in regard to prevention and awareness of meningococcal disease, the majority $(57 \%, \mathrm{~N}=4)$ of case study universities argued that passive approaches were cheaper and lowered the amount of competing health related information and messages already present within university communities. ${ }^{17-23}$ In addition, four of case study universities stated that due to the fact that the incidence rate of meningococcal disease was significantly lower to that of other health conditions or risks such as depression amongst university students, an active approach of prevention and awareness would take away from other more prevalent issues. ${ }^{17-23}$ 


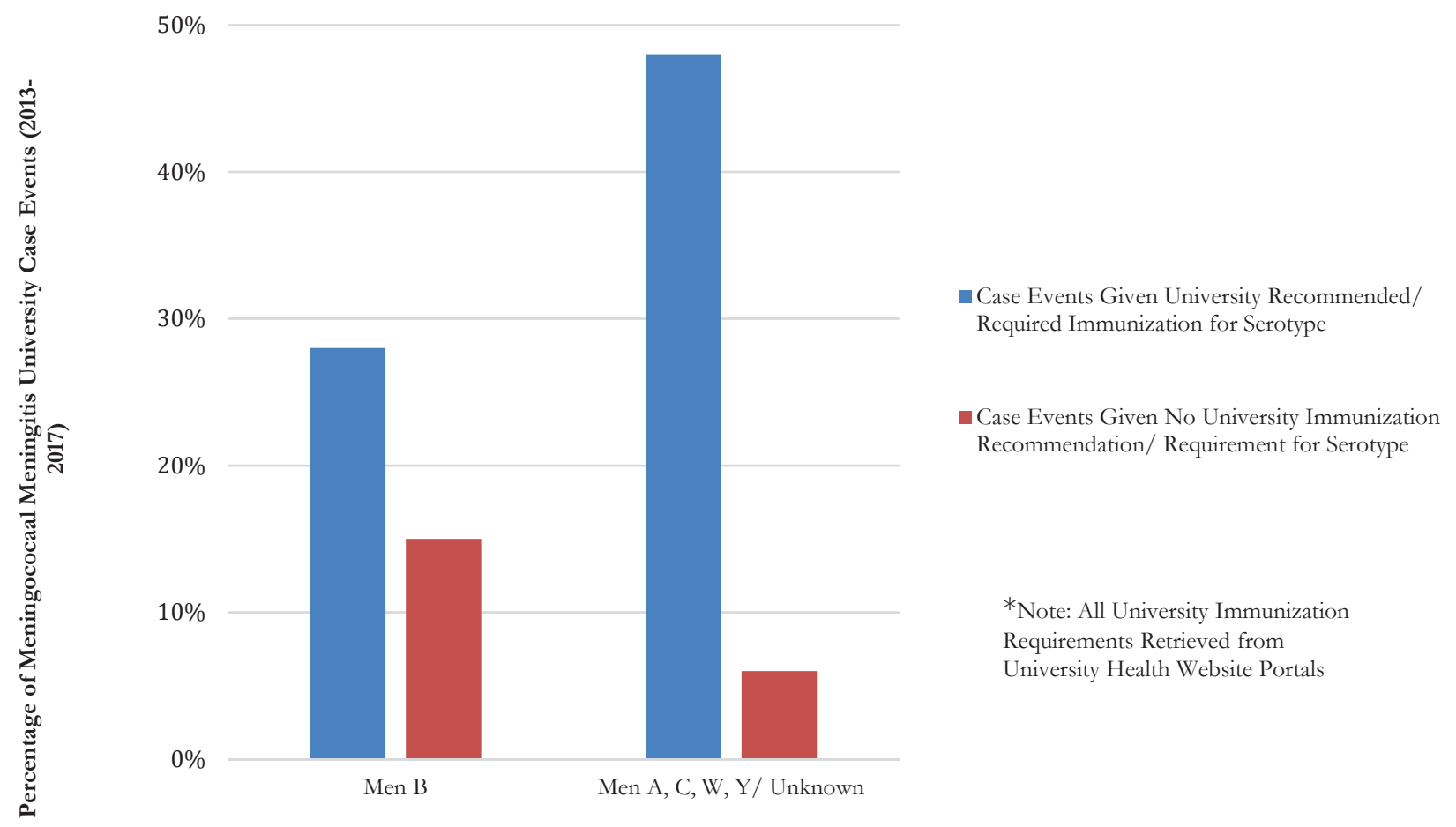

Type of Meningococcal Meningitis Serotype Case Event

Figure 2. US University Meningococcal Meningitis Case Events (2013-2017) Given University Immunization Requirements ${ }^{13}$

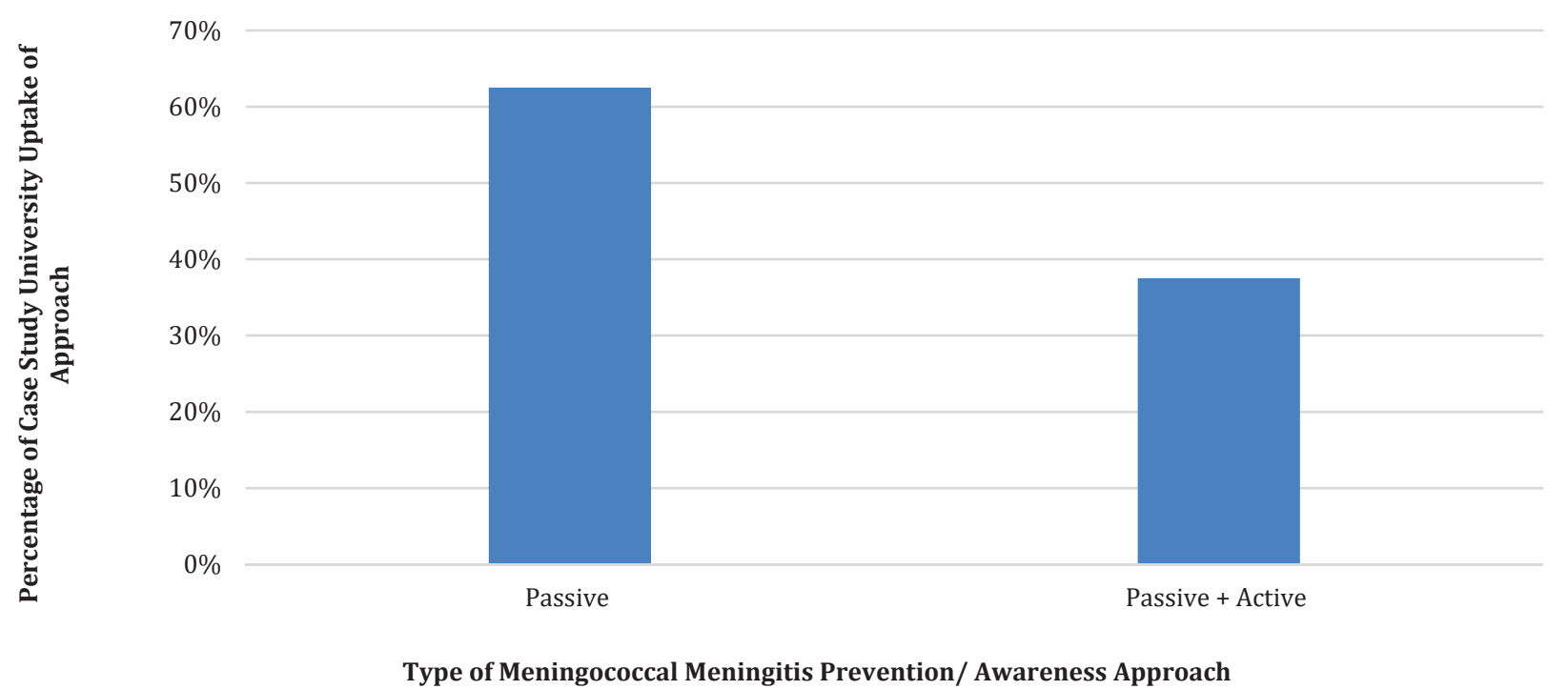

Figure 3. Distribution of Prevention and Awareness Approaches across US Case Study Universities. ${ }^{17-23}$ 
Active approach universities included Kalamazoo College, who post outbreak, made an effort to educate more of their student population on the risks and early symptoms of meningococcal disease. Specific methods used included active distribution of meningococcal disease cards and display of meningitis prevention videos and presentations to students at orientation, in addition to hosting a health forum. Apart from active approaches alone, Kalamazoo College also used passive approaches in spreading awareness by sending out an informative email during the summer months. According to some Kalamazoo College student health center staff, distribution of mail during summer months also targeted and informed parents, and not just students. ${ }^{17}$

In the aftermath of most outbreaks or cases occurring on campuses, the majority of university student health center staff stated that their universities were pushed to improve their preventative measures for meningococcal disease on their campuses. Specific improvements apart from mass vaccination campaigns at large outbreak institutions, included postings of CDC protocol and recommendations for meningococcal disease vaccination and prevention on electronic student health center portals. Although majority of universities stated that they took more of a passive approach in spreading awareness and preventing meningococcal disease, it is important to note that during or immediately after specific outbreaks or cases occurred, active responses were taken. ${ }^{17-23}$

Apart from current approaches to awareness and prevention of meningococcal disease on university campuses, case study universities were also asked to list creative new approaches that they thought might be more effective. In response, $80 \%(\mathrm{~N}=6)$ of suggestions were targeted at spreading awareness about the specific symptoms of meningococcal disease. Specific strategies centered on symptom awareness included educating parents, posting flyers around campus, and contacting students through their emails.17-23 Some suggestions included the posting of flyers not only in large public spaces like the student union, but also within entry ways of residence halls. In addition to spreading awareness of meningococcal symptoms to university communities, other suggestions included working with other outside providers and companies to not only improve student health care but also the stocking of specific ACWY Conjugate vaccines at student health centers. In stocking vaccination supplies, students would have easy vaccine accessibility upon consultation.

\section{DISCUSSION}

After gathering case specific data and interviewing health directors and health center staff, it was evident that the majority of university prevention and awareness programs were retrospective and passive rather than prospective and active. Due to money and the higher prevalence of other health concerns on campuses (e.g. depression, alcoholism, opiate use), active campaign efforts to control meningococcal disease were not a priority until outbreaks occurred on their campuses. ${ }^{17-23}$

Although some university approaches to awareness and prevention were more passive, it did not mean that universities were not prioritizing the importance of meningococcal disease on their campuses. Results revealed that while all US universities were required to follow state health regulations, some universities went above and beyond in choosing to follow ACIP guidelines, in addition to providing awareness and vaccination education, before or after meningococcal meningitis case occurred have been present on their campuses. An example of this can be seen by the response efforts during the University of Oregon outbreak of 2015.

Between early January and June 2015, University of Oregon had an outbreak of serotype B Neisseria meningococcemia. Although the university had not experienced quite as large an outbreak previously, as cases were confirmed, University of Oregon and state health department officials worked together to prevent further spread of the disease. ${ }^{24}$ As soon as cases were confirmed, victims of the outbreak (see Table 3) were interviewed about their main contacts, so the university could identify susceptible students and staff. Overall the university identified more than 800 of its students and staff, believed to have been in contact with victims of the outbreak. ${ }^{24}$ Individuals having close contact with victims for a least a four-hour cumulative period within a one-week period were also provided with preventative medications other than antibiotics to help further prevent the spread of disease. ${ }^{25}$

Even though cases occurred gradually, University of Oregon staff and public health officials pushed for a mass vaccination campaign. The recent licensure of Men B vaccinations (Bexsero and Trumenba), meant that future cases of the serotype B Neisseria meningococcemia, responsible for the university outbreak, could be prevented. After the sixth case was confirmed and public health officials realized that providing antibiotics would not fully prevent the spread of disease, University of Oregon parents were also contacted and encouraged to get their children vaccinated. While undergraduates and first year students living in dormitories were mainly targeted to receive vaccination, graduate students who lived in campus housing were also urged to become vaccinated. ${ }^{26}$ By late February and early March of 2015, University of Oregon launched a mass vaccination campaign, where all 22,000 undergraduates would be encouraged to participate in a two-step vaccination regime. In order to cover costs of vaccination, the university worked with insurance companies to ensure complete vaccination coverage for their students. For uninsured students, University of Oregon health directors and staff attempted to get uninsured individuals on the Oregon Health Plan or provided 
free shots from donated doses. ${ }^{27}$ While vaccination was one of the best methods of prevention, marketing and awareness of the meningococcal disease became a necessity to encourage undergraduate students to become vaccinated. According to media coverage of the event, "around campus posters [featured] smiling student athletes showing off the arm where they were vaccinated and sporting a green or gold adhesive bandage with the school logo on it," were one of many attempts to encourage vaccination. ${ }^{28}$ In addition, short wait times combined with free swag and food, worked to encourage students to become vaccinated. Although the University of Oregon outbreak occurred between January and May of 2015, the university still attempts to spread awareness of the disease and its effects through online portals and information pages on their student health center website. ${ }^{23}$

\begin{tabular}{|c|c|c|c|c|}
\hline Case Number & Date* & $\begin{array}{c}\text { Type of Meningococcal } \\
\text { Disease Contracted }\end{array}$ & Demographics of Victim & Status \\
\hline $\mathbf{1}$ & $1 / 13 / 2015$ & Neisseria meningococcemia & Residence Hall Resident & Recovered \\
\hline $\mathbf{2}$ & $2 / 2 / 2015$ & Neisseria meningococcemia & Private Residence Resident & Recovered \\
\hline $\mathbf{3}$ & $2 / 8 / 2015$ & Neisseria meningococcemia & UNKNOWN & Recovered \\
\hline $\mathbf{n}$ & $2 / 17 / 2015$ & Neisseria meningococcemia & $\begin{array}{c}\text { 18 Years Old, Female, } \\
\text { Acrobatics and Tumbling } \\
\text { Team }\end{array}$ & Death \\
\hline $\mathbf{5}$ & UNKNOWN & Neisseria meningococcemia & UNKNOWN & Recovered \\
\hline & $3 / 18 / 2015$ & Neisseria meningococcemia & $\begin{array}{c}\text { 20 Year Old, lived in off } \\
\text { campus fraternity, } \\
\text { experienced flu-like } \\
\text { symptoms }\end{array}$ & Recovered \\
& $529 / 2015$ & Neisseria meningococcemia & $\begin{array}{c}52 \text { Year Old father of } \\
\text { University of Oregon } \\
\text { student }\end{array}$ & Recovered \\
\hline 7 & & & \\
\hline
\end{tabular}

*Dates may not be the exact date victims started showing symptoms, but rather when the media was notified of confirmed cases occurring.

Table 3. Example Case Study of Meningococcal Meningitis: University of Oregon. ${ }^{23-28}$

Although large vaccination campaigns are effective (as seen by University of Oregon efforts), Men B vaccination was only licensed in 2015, explaining university trends to follow ACIP protocol and only recommend it to students. In this way, while some universities did not require Men B or sometimes Men ACWY vaccination, they still ensured that university students had access to vaccination programming. According to interviewed university health center staff, passive approaches to the prevention of meningococcal disease were more cost effective and less likely to cause fear amongst students. ${ }^{17-23}$ However, if students were not aware of specific symptoms of the disease, there was the potential for college students to confuse meningococcal disease symptoms to the flu, or even perhaps a hangover. ${ }^{29}$ According to a study conducted at Ohio University between 2008 and 2010, specific susceptibility factors on university campuses included individuals in Greek life, having more than one kissing partner, or drinking alcoholic beverages. ${ }^{29}$ As a result, university culture and pre-existing conditions might have played a large role in not only contraction of meningococcal disease but also the identification and response time in seeking immediate care. Perhaps, this is where passive approaches can be made to be more effective.

Given the susceptibility of university students, who may live in dormitories, have multiple kissing partners, smoke, or frequently are victims of hangovers, it is important that universities are educating their university communities. Although meningococcal disease continues to be a rare disease, continued outbreaks of meningococcal disease reported to the National Meningitis Association between the years of 2013-2017, show that there are still approaches to prevention and awareness that can be improved upon. Universities that seemed to get good feedback from students and their university communities on meningococcal prevention efforts included that of Kalamazoo College. Reasoning behind positive feedback could include the fact that active meningococcal awareness and prevention efforts taken by Kalamazoo Health staff, involved more campus involvement. Specific events requiring more involvement included large health forums or orientation sessions that not only addressed meningococcal disease but also addressed other health and safety risks and offered resources to prevent them. ${ }^{17}$

In many ways, by involving more of the university community in organizing such events or presenting meningococcal disease information at events that reach a larger population of students, more university students might be more inclined to learn more about preventative methods and spread awareness about meningococcal disease. For a few universities in the United Kingdom, active methods such as spreading prevention and awareness strategies at orientation health information sessions and organizing health campaign weeks, have helped in educating university campus communities. ${ }^{30}$ In comparison to many US universities, according to representatives from Meningitis Now and the Meningitis Research Foundation, some British universities have sought to improve their meningococcal prevention and awareness efforts by partnering with local meningitis organizations. ${ }^{29,30}$ One of 
the largest set-backs with active prevention and awareness campaigns, voiced by case study universities, was cost. Nevertheless, by partnering with national meningitis organizations, universities could cut back on costs, and allow organizations to organize campaign programs and disburse awareness and prevention information to university students.

Another solution going forward, might be to include aspects of the Health Belief Model in prevention and awareness efforts on university campuses. In many ways, one of the most important parts of prevention and awareness is making sure that all parties involved, that being university students, health center workers, and state health department officials, all equally value and believe in the end goal of wanting to decrease the amount of meningococcal disease cases seen at university institutions. The Health Belief Model, a model designed to address the cognitive behaviors of reducing the outcome of a disease, would encourage individuals to acknowledge the need for improvement and engagement or action in regard to prevention efforts. ${ }^{32}$ Through the use of direct focus groups and belief and realization that meningococcal prevention can be improved on university campuses, protocols and active or passive approaches can be made to be more effective.

\section{CONCLUSION}

The findings from this research not only brought forth helpful insight into university meningococcal disease prevention and awareness efforts, but also further methods to improve them(e.g. university community participation and involvement in advocacy, health forums, targeted educational programming on meningococcal signs and symptoms, passive posters and incentives encouraging vaccination). Although meningococcal disease has been on the decline since before ACWY vaccines were legalized, efforts to improve meningococcal disease prevention and awareness on campuses have improved. Approaches to meningococcal disease prevention and awareness at most university institutions were passive in approach, however some universities still adopted active approaches. Even though active approaches are often sometimes more expensive, partnering with local health or meningitis organizations might be a way that universities can decrease cases occurring at their universities, while being cost effective. Even though many of the larger outbreaks occurring amongst universities between the years of 2013-2017 were serotype B, it should be noted that there were no Men B vaccinations available until 2015. Given the recent licensure of Men $\mathrm{B}$ it is understandable why universities followed ACIP and CDC guidelines of only recommending the Men B vaccine to susceptible populations. Going forward, analysis on the relation between the magnitude of state meningococcal prevention requirements (e.g. vaccination, education) and geographical case occurrences will be needed, so as to limit confounding variables and identify whether university prevention or state requirements have more of an effect on meningococcal disease incidence. In addition, more case studies will be needed to confirm the best preventative methods for meningococcal disease at U.S. universities. Nevertheless, case study universities utilized in this study provide a valuable case for passive approaches being more cost effective and more easily implemented into university communities. Meningococcal disease continues to be the most common amongst individuals in their late adolescence, which sadly includes majority of first year students entering university. While the effect of meningococcal disease can be detrimental to brain function and circulation, meningococcal disease does not have to be a threat to older adolescents if preventative methods and protocol are valued at university campuses.

\section{ACKNOWLEDGEMENTS}

The author thanks Dr. Randall Harris, OSU College of Public Health, Professor of Epidemiology. Many thanks is also given to all the interviewed US university health staff and international and national organizations, for their participation in the study.

\section{REFERENCES}

1. Centers for Disease Control and Prevention (March 2013). Prevention and Control of Meningococcal Disease, Recommendation of the Advisory Committee on Immunization Practices (ACIP). Morbidity and Mortality Weekly Report, Center for Disease Control. 2 (62): RR02; 1-22. Retrieved from https:// wnw..cdc.gov/ mmwr/preview/ mmwrhtml/ rr6202a1.btm.

2. National Health Service (2016). Meningitis. Retrieved from https:// mwn.nhs.uk/conditions/meningitis/causes/.

3. Center for Disease Control and Prevention. Surveillance. Retrieved from bttps://wnww.cdc.gov/meningococcal/surveillance/index. html.

4. Villena,R., Safadi,M., Valenzuela, M. T., Torres, J.P., Finn, A., \& O’Ryan, M. (2018). Global Epidemiology of Serogroup B Meningococcal Disease and Opportunities for Prevention with Novel Recombinant Protein Vaccines. Human Vaccines \& Immunotherapeutics. 14(5), 1042-1057. doi:10.1080/21645515.2018.1458175.

5. Rouphael, Nadine G., and David S. Stephens (2012). Neisseria Meningitidis: Biology, Microbiology, and Epidemiology. Methods in molecular biology (Clifton, N.J.)799: 1-20. PMC. doi: 10.1007/978-1-61779-346-2_1.

6. El Bashir H, Laundy M, Booy R (2003). Diagnosis and Treatment of Bacterial Meningitis. Archives of Disease in Childhood. 88(615-620). doi:10.1136/adc.88.7.615.

7. Harrison LH, Dwyer DM, Maples CT, Billmann L (1999). Risk of Meningococcal Infection in College Students. JAMA.281 (20), 1906-1910. doi:10.1001/jama.281.20.1906. 
8. Advisory Committee on Immunization Practices (June 2000). Meningococcal Disease and College Students. Morbidity and Mortality Weekly Report, Center for Disease Control. 7(49): RRO7; 11-20. Retrieved from https:// www.cdc.gov/ mmwr/preview/mmwrhtml/ rr4907a2.htm.

9. MacNeil J.; Patton M. (2017). Manual for the Surveillance of V accine-Preventable Diseases. National Center for Immunization and Respiratory Diseases, CDC. Retrieved from https://www.cdc.gov/vaccines/pubs/surv-manual/chpt08-mening.html.

10. Kuhdari, P., Stefanati, A., Lupi, S., Valente, N., \& Gabutti, G. (2016). Meningococcal B vaccination: real-world experience and future perspectives. Pathogens and Global Health, 110(4-5), 148-156. doi:10.1080/20477724.2016.1195072.

11. Friedman, Jordan (2016). National Universities Where the Most Students Live on Campus. US News and World Report. Retrieved from https:/ / www.usnews.com/ education/ best-colleges/the-short-list-college/ articles/2016-11-15/11-national-universities-where-the-moststudents-live-on-campus.

12. Immunization Action Coalition (Feb 2018). Meningococcal ACWY. National Center for Immunization and Respiratory Diseases, CDC. Retrieved from http://wmw.immunize.org/askexperts/experts_meningococcal_acwy.asp.

13. National Meningitis Association. Retrieved from https:// wmw.nmaus.org/.

14. University of Missouri Student Health Center (2018). MU Immunizations Policy. Retrieved from https:/ / studenthealth.missouri.edu/forms-policies/mu-immunizations-policy/.

15. Advisory Committee on Immunization Practices (2011). General Recommendations on Immunization --- Recommendations of the Advisory Committee on Immunization Practices (ACIP): Morbidity and Mortality Weekly Report. Recommendations and Reports. 60(2): RR02; 1-64. Retrieved from https:// www.cdc.gov/ mmwr/preview/ mmwrhtml/ rr6002a1.htm.

16. Advisory Committee on Immunization Practices (October 2015). Use of Serogroup B Meningococcal Vaccines in Adolescents and Young Adults: Recommendations of the Advisory Committee on Immunization Practices. Morbidity and Mortality Weekly Report, Center for Disease Control: 64(41);1171-6. Retrieved from https:// www.cdc.gov/ mmwr/preview/ mmwrhtml/ mm6441a3.htm.

17. Kalamazoo College Health Staff, personal communication, June 2017.

18. Westchester University Health Staff, personal communication, June 2017.

19. Palomar Community College Health Staff, personal communication, June 2017.

20. Missouri University Health Staff, personal communication, June 2016.

21. University of California Santa Barbara Health Staff, personal communication, July 2016.

22. Georgia Tech Health Staff, personal communication, July 2016.

23. University of Oregon Student Health Center Staff, personal communication, October 27, 2016.

24. KVAL News (Jan 2015). UO Student Hospitalized with Potentially Deadly Infectious Disease. KVAL. Retrieved from https:/ / kval.com/ news/ local/ uo-student-hospitalized-with-potentially-deadly-infectious-disease.

25. Herriman, Robert (Feb 2015). University of Oregon outbreak: 3 rd meningitis case reported. Outbreak News Today. Retrieved from http://outbreaknewstoday.com/university-of-oregon-outbreak-3rd-meningitis-case-reported-25954.

26. Capitano B; Dillon K; LeDuc A; Atkinson B; Burman C (January 2019). Experience Implementing a University-Based Mass Immunization Program in Response to a Meningococcal B Outbreak. Human Vaccines and Immunotherapies. 3 (717-724). doi: 10.1080/21645515.2018.1547606.

27. Hammond, Betsy (Feb 2015). University of Oregon meningitis vaccination will be largest in US since approval of new drug. The Oregonian. Article Retrieved from http:/ / www.oregonlive.com/education/index.ssf/2015/02/university_of_oregon_meningiti.html.

28. Hanrahan, Mark (March 2015). $\sigma^{\text {th }}$ Student in Oregon Infected with Meningitis Bacteria. USA Today. Article Retrieved from https:/ / eu.usatoday.com/story/news/nation/2015/03/19/meningitis-outbreak-oregon/25049737/.

29. Clark TA, Cohn AC, DiOrio M, Garcia J, Gaskell JR, King L, Machesky K, MacNeil JR, Mandal S, Messonnier NE, Mayer LW, Plikaytis BD, Quinn K, Schmink SE, Wang X, Wu HM (Aug 2013). Prolonged university outbreak of meningococcal disease associated with a serogroup B strain rarely seen in the United States. Clinical Infectious Diseases, National Center for Biotechnology Information.;57(3), 344-8. doi: 10.1093/cid/ cit243.

30. Meningitis NOW, personal communication, June 222016.

31. Meningitis Research Foundation, personal communication, June 232016.

32. Wagner, A. L., Boulton, M. L., Sun, X., Mukherjee, B., Huang, Z., Harmsen, I. A., Zikmund-Fisher, B. J. (2017). Perceptions of measles, pneumonia, and meningitis vaccines among caregivers in Shanghai, China, and the health belief model: a cross-sectional study. BMC pediatrics, 17(1), 143. doi:10.1186/s12887-017-0900-2.

\section{ABOUT THE AUTHOR}

Mikafui Dzotsi is a recent graduate of The Ohio State University. Mikafui's interest in investigating the prevention and awareness of meningococcal disease on college campuses was sparked by her exposure to epidemiology as a Public Health Major during her undergrad. She is currently working towards completing her Master Degree in Epidemiology. She hopes that her degree will enable her to create sustainable solutions for the prevention of global health issues. 


\section{PRESS SUMMARY}

Even though meningococcal disease is rather rare and on the decline, college students, who often live in dormitories or close quarters, remain one of the most susceptible populations. Recent outbreaks at some US universities have brought more attention to the importance of good vaccination policies and disease prevention efforts on university campuses. This study reviews the incidence of specific meningococcal meningitis serotypes occurring at US universities (2013-2017), in addition to university prevention and awareness efforts. Through means of this analysis, this study functions to identify more effective methods for meningitis control on college campuses. 